\title{
Calcium reconstitutes high rates of oxygen evolution in polypeptide depleted Photosystem II preparations
}

\author{
Demetrios F. Ghanotakis, Gerald T. Babcock* and Charles F. Yocum \\ Division of Biological Sciences, The University of Michigan, Ann Arbor, MI 48109-1048 and *Department of \\ Chemistry, Michigan State University, East Lansing, MI 48824-1322, USA
}

Received 29 November 1983

\begin{abstract}
Exposure of highly resolved Photosystem II preparations to $2 \mathrm{M} \mathrm{NaCl}$ produces an $80 \%$ inhibition of oxygen-evolution activity concomitant with extensive loss of two water-soluble polypeptides (23 and $17 \mathrm{kDa}$ ). Addition of $\mathrm{Ca}^{2+}$ to salt-washed PS II membranes causes an acceleration in the decay of $Z^{+}$, the primary donor to $\mathrm{P}-680^{+}$, and we show here that this acceleration is due to reconstitution of oxygenevolution activity by $\mathrm{Ca}^{2+}$. Other cations $\left(\mathrm{Mg}^{2+}, \mathrm{Mn}^{2+}, \mathrm{Sr}^{2+}\right)$ are much less effective in restoring oxygen evolution. On the basis of these observations we propose that $\mathrm{Ca}^{2+}$, perhaps in concert with the $23 \mathrm{kDa}$ polypeptide, is an essential cofactor for electron transfer from the ' $S$ '-states to $Z$ on the oxidizing side of
\end{abstract} PS II.

Photosystem II Oxygen evolution Polypeptide Calcium

\section{INTRODUCTION}

Photosynthetic oxygen evolution is significantly inhibited when PS II membrane preparations are treated with $2 \mathrm{M} \mathrm{NaCl}[1,2]$; extensive removal of the 17 and $23 \mathrm{kDa}$ polypeptides is observed but functional manganese is not perturbed by this treatment. Authors in [3] reported that treatment of inside-out spinach thylakoid vesicles with $250 \mathrm{mM} \mathrm{NaCl}$ inhibited $75 \%$ of oxygen evolution activity; this inhibition was also accompanied by the release of the 17 and $23 \mathrm{kDa}$ polypeptides. Addition of the purified $23 \mathrm{kDa}$ polypeptide to the extracted inside-out vesicles restored about $60 \%$ of the activity lost by salt washing. Even though the 23 and $17 \mathrm{kDa}$ polypeptides have been purified and their amino acid content is known [4], it is not

Abbreviations: DCBQ, 2,5-dichloro-p-benzoquinone; DCMU, 3-(3,4-dichlorophenyl)-1,1-dimethylurea; $\mathrm{Fe}^{\mathrm{III}} \mathrm{CN}$, potassium ferricyanide; Hepes, $N$-2-hydroxyethylpiperazine- $N^{\prime}$-2-ethanesulfonic acid; Mes, 4-morpholinoethanesulfonic acid; PS II, Photosystem II clear what role they play in oxygen evolution. All investigations so far have correlated loss of a $33 \mathrm{kDa}$ polypeptide with loss of functional manganese, whereas a structural role has been postulated for the 23 and the $17 \mathrm{kDa}$ species $[1,3]$.

We have examined the behavior of PS II preparations after high-salt extraction and have found that $80 \%$ of the control oxygen evolution activity is restored upon addition of $\mathrm{CaCl}_{2}$. $\mathrm{A}$ parallel study of the EPR signal arising from the primary donor to $\mathrm{P}-680^{+}, \mathrm{Z}^{+}$, strongly suggests a site of $\mathrm{Ca}^{2+}$ action on the oxidizing side of PS II.

\section{MATERIALS AND METHODS}

Subchloroplast membranes, free of Photosystem I and having high rates of oxygen evolution, were prepared as in [1,5]. Salt treatment to release polypeptides from the PS II complex was carried out by incubation of the preparation in $2 \mathrm{M} \mathrm{NaCl}(\mathrm{pH} \mathrm{6.0)}$ on ice for $1 \mathrm{~h}$ in the dark. After centrifugation the membranes were washed once with SMN (0.4 M sucrose $/ 50 \mathrm{mM}$ Mes, $\mathrm{pH}$ $6.0 / 15 \mathrm{mM} \mathrm{NaCl}$ ) and then stored in the same buf- 
fer. Calcium content in the PS II preparations was determined at $4227 \AA$ with a Jarcll-Ash atomic absorption/flame emission spectrometer. Samples for the above analysis were prepared as follows: PS II preparations were pelleted by centrifugation and the pellets were resuspended in $0.1 \mathrm{~N} \mathrm{HCl}$. The suspensions were heated for $4 \mathrm{~min}$ at $80^{\circ} \mathrm{C}$ and then centrifuged for $5 \mathrm{~min}$ at $10000 \times \mathrm{g}$; the clear supernatants were combined with the supernatants from a subsequent wash and were analyzed by flame emission spectroscopy. Gel electrophoresis was carried out as in [6] with the modification that $2.5 \mathrm{M}$ urea was present in the gel and in denaturing solutions.

EPR spectroscopy was carried out on a Bruker ER-200D spectrometer operated at X-band and interfaced to a Nicolet 1180 computer. Instrument modifications as well as the xenon flash lamp cir-

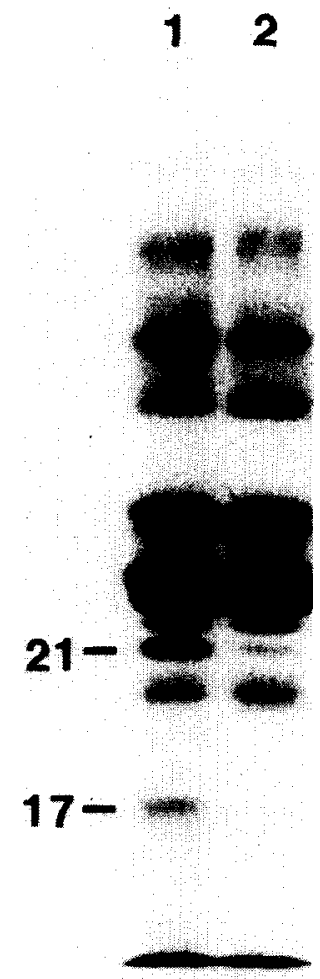

Fig.1. Gel electrophoresis patterns: (1) of the untreated PS II complex; (2) after high-salt treatment. The gel contains $2.5 \mathrm{M}$ urea. Under these conditions the apparent molecular mass of the $23 \mathrm{kDa}$ polypeptide is shifted to $21 \mathrm{kDa}$ as shown on the gel. cuitry and the protocol followed in signalaveraged, flashing-light kinetic experiments are described in [7].

\section{RESULTS}

Fig. 1 shows that exposure of PS II membranes to $2 \mathrm{M} \mathrm{NaCl}$ for $1 \mathrm{~h}$ at $\mathrm{pH} 6.0$ produces an extensive depletion of two polypeptides (17 and $23 \mathrm{kDa}$ ). As we reported earlier, this treatment generates $Z^{+}$with an increased decay time [1]. A further analysis of the decay of flash-induced $Z^{+}$in salt-washed PS II membranes produced the results shown in fig.2, where addition of $\mathrm{Ca}^{2+}$ induces an accelerated decay of the radical. The effect shown in fig. 2 could be due either to the induction of a fast back-reaction from $Q^{-}$to $Z^{+}$, or to an effect of $\mathrm{Ca}^{2+}$ on the oxidizing side of PS II. The latter is shown to be true by the data of fig.3, where added $\mathrm{Ca}^{2+}$ reconstitutes high rates of oxygen evolution activity in the salt-washed PS II preparations.

An examination of the $\mathrm{Ca}^{2+}$ content of saltwashed PS II preparations revealed that about

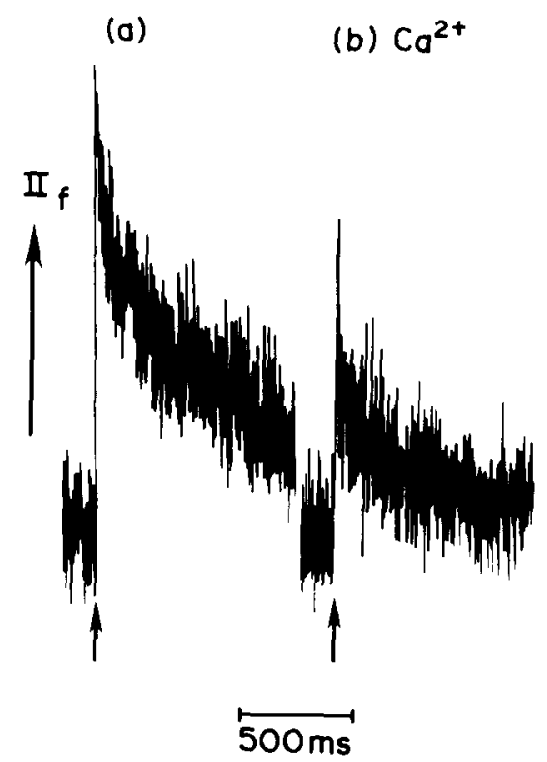

Fig.2. Kinetic transients for $\mathrm{Z}^{\dagger}$ at room temperature in high-salt-treated PS II complex. An equimolar mixture of ferricyanide and ferrocyanide was used as an acceptor system. (a) No further addition; (b) $10 \mathrm{mM} \mathrm{CaCl}_{2}$. Each kinetic trace is the average of 200 flashes. Time constant $=1 \mathrm{~ms}$ and dark time between flashes $t_{\mathrm{d}}=$ $3.5 \mathrm{~s}$. 


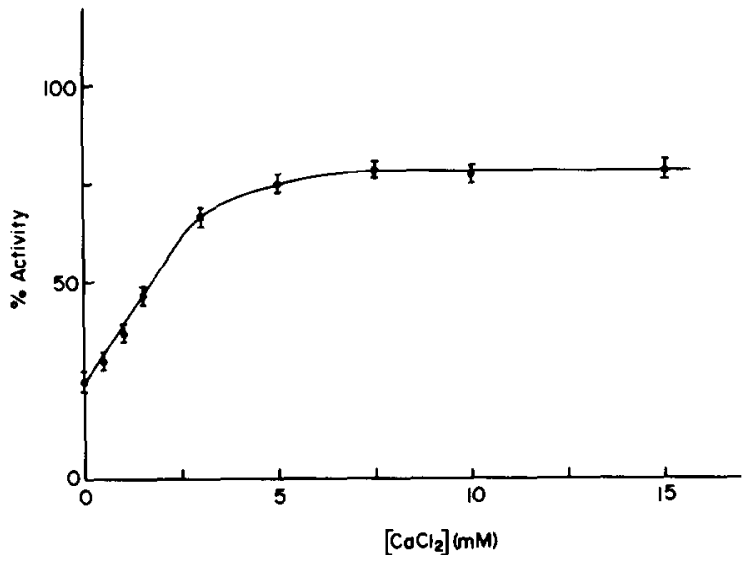

Fig.3. Rates of oxygen evolution as a function of added $\mathrm{CaCl}_{2}$. High-salt-treated PS II complex was illuminated with continuous light in a $0.4 \mathrm{M}$ sucrose $/ 50 \mathrm{mM}$ Mes (pH 6.0) buffer containing $\mathrm{CaCl}_{2}$ as indicated, $6 \mu \mathrm{g}$ chlorophyll $/ \mathrm{ml}, 250 \mu \mathrm{M}$ dichlorobenzoquinone and $3.5 \mathrm{mM}$ ferricyanide (control activity $\left( \pm \mathrm{Ca}^{2+}\right)$ : $\left.780 \mu \mathrm{mol} \mathrm{O} 2 \cdot \mathrm{mg} \mathrm{Chl}^{-1} \cdot \mathrm{h}^{-1}\right)$.

$40 \%$ of the $\mathrm{Ca}^{2+}$ was removed by exposure to $2 \mathrm{M}$ $\mathrm{NaCl}$. Control PS II membranes contained 0.84 gatom $\mathrm{Ca} / \mathrm{mol} \mathrm{Chl}$; in salt-washed preparations, 0.52 gatom $\mathrm{Ca} / \mathrm{mol} \mathrm{Chl}$ was found. Since the salt treatment of the PS II complex could remove other cations as well as $\mathrm{Ca}^{2+}$, we examined the ability of several divalent cations to restore oxygen evolution activity. These data are summarized in table 1 . At the concentration shown $(15 \mathrm{mM}), \mathrm{Ca}^{2+}$ is most effective in restoring activity. None of the other cations can produce oxygen-evolution activity equal to that of $\mathrm{Ca}^{2+} ; \mathrm{Mn}^{2+}$ is slightly inhibitory. We
Table 1

Effects of cations on rate of oxygen evolution in highsalt-treated PS II preparations

\begin{tabular}{lcc}
\hline Additions & $\begin{array}{c}\text { Activity } \\
\left(\mu \mathrm{mol} \mathrm{O}_{2} \cdot \mathrm{mg}\right. \\
\left.\mathrm{Chl}^{-1} \cdot \mathrm{h}^{-1}\right)\end{array}$ & \% Activity \\
\hline None & 196 & 25 \\
$\mathrm{CaCl}_{2}(15 \mathrm{mM})$ & 616 & 79 \\
$\mathrm{MgCl}_{2}(15 \mathrm{mM})$ & 202 & 26 \\
$\mathrm{SrCl}_{2}(15 \mathrm{mM})$ & 330 & 42 \\
$\mathrm{MnCl}_{2}(15 \mathrm{mM})$ & 160 & 20 \\
$\mathrm{DCMU}(80 \mu \mathrm{M})_{\mathrm{CaCl}}(15 \mathrm{mM})+$ & 28 & 3 \\
$\mathrm{DCMU}(80 \mu \mathrm{M})$ & 50 & 6 \\
\hline a Control activity $\left( \pm \mathrm{Ca}^{2+}\right): 780 \mu \mathrm{mol} \mathrm{O}_{2} \cdot \mathrm{mg} \mathrm{Chl}^{-1} \cdot \mathrm{h}^{-1}$ \\
(conditions the same as those in fig.3)
\end{tabular}

emphasize here that the relatively high concentrations of $\mathrm{Ca}^{2+}$ required to reconstitute activity implies that the cation is weakly bound to the membrane; this is borne out by the observations that we cannot incubate PS II membranes at high concentrations with $\mathrm{Ca}^{2+}$ and then successfully dilute the suspension for assay of activity, and that EGTA at appropriate concentrations blocks reconstitution (not shown). The data of table 2 show that the ability of $\mathrm{Ca}^{2+}$ to reconstitute oxygen evolution activity is independent of the acceptor system used to assay the PS II preparation, although as we reported earlier [1,5], a lipophilic redox mediator such as DCBQ produces the highest rates of oxygen evolution activity.

Table 2

Effect of calcium on rate of oxygen evolution in high-salt-treated PS II preparations in the presence of various acceptor systems

\begin{tabular}{lcc}
\hline Acceptor system & Additions & $\begin{array}{c}\text { Activity } \\
\left(\mu \mathrm{mol} \mathrm{O}_{2} \cdot \mathrm{mg} \mathrm{Chl}^{-1} \cdot \mathrm{h}^{-1}\right)\end{array}$ \\
\hline $\mathrm{DCBQ}(250 \mu \mathrm{M})$ & None & 180 \\
& $\mathrm{CaCl}_{2}(15 \mathrm{mM})$ & 610 \\
$\mathrm{Fe}^{\mathrm{III}} \mathrm{CN}(3.5 \mathrm{mM})$ & None & 30 \\
& $\mathrm{CaCl}_{2}(15 \mathrm{mM})$ & 130 \\
$\mathrm{DCBQ}(250 \mu \mathrm{M})+\mathrm{Fe}^{\mathrm{III}} \mathrm{CN}(3.5 \mathrm{mM})$ & None & 185 \\
& $\mathrm{CaCl}_{2}(15 \mathrm{mM})$ & 600 \\
\hline
\end{tabular}

${ }^{a}$ Control activity $\left( \pm \mathrm{Ca}^{2+}\right.$ ): $780 \mu \mathrm{mol} \mathrm{O} \mathrm{O}_{2} \cdot \mathrm{mg} \mathrm{Chl}^{-1} \cdot \mathrm{h}^{-1}$ (conditions the same as those in fig.3) 


\section{DISCUSSION}

Several previous studies on cyanobacteria $[8,9]$ and higher plant chloroplast systems [10,11] have implicated $\mathrm{Ca}^{2+}$ as a possible cofactor in PS IIcatalyzed electron transfer, although speculations as to its role have not produced a consensus on a specific side of action. Likewise, the role of watersoluble polypeptides ( 23 and $17 \mathrm{kDa})$ in reactivating oxygen evolution activity has not been established. Authors in [3] demonstrated a requirement for the $23 \mathrm{kDa}$ species, but this protein contains no appreciable amounts of bound manganese nor does its release from inside-out thylakoid vesicles perturb the membrane-bound manganese required for oxygen evolution activity. As we show here, $\mathrm{Ca}^{2+}$ can reconstitute oxygen evolution activity in salt-washed membranes where the 23 and $17 \mathrm{kDa}$ polypeptides are depleted. This effect of $\mathrm{Ca}^{2+}$ is located on the oxidizing side of PS II at a site where electron transfer from the $S$-states to $Z^{\ddagger}$ is facilitated.

From the data presented here, we can propose 3 hypotheses concerning the roles of polypeptides and $\mathrm{Ca}^{2+}$ in oxygen evolution activity. The first hypothesis would state that $\mathrm{Ca}^{2+}$ by itself is an essential cofactor for oxygen evolution. This assertion is not supported by the results presented here, since $\mathrm{Ca}^{2+}$ cannot be made to bind to the PS II preparations in such a way as to reconstitute activity under conditions where the cation is present at low concentrations. The second hypothesis would state that the $23 \mathrm{kDa}$ is essential for oxygen evolution activity and that its role can be mimicked by $\mathrm{Ca}^{2+}$. This model is not entirely satisfactory because:

(i) Extensive depletion of the $23 \mathrm{kDa}$ polypeptide does not entirely inhibit oxygen evolution activity (see also [2]);

(ii) Release of the $23 \mathrm{kDa}$ polypeptide results in concomitant removal of $\mathrm{Ca}^{2+}$.

The third hypothesis holds that both $\mathrm{Ca}^{2+}$ and the $23 \mathrm{kDa}$ polypeptide are necessary for optimal rates of oxygen evolution activity. We favor this model because:

(i) The absence of the $23 \mathrm{kDa}$ polypeptide creates a situation in which loosely-bound $\mathrm{Ca}^{2+}$ reconstitutes activity; (ii) Addition of EGTA to PS II preparations at pH 6.0 does not inactivate oxygen evolution, but does prevent reconstitution by $\mathrm{Ca}^{2+}$ of activity in salt-washed preparations;

(iii) The variety of systems (intact thylakoids, cyanobacterial cells and membrane vesicles) which have been demonstrated to require $\mathrm{Ca}^{2+}$ for PS II activity must certainly include preparations where $\mathrm{Ca}^{2+}$ and not the $23 \mathrm{kDa}$ polypeptide, has been removed to create the lesion in PS II.

Experiments are now in progress to examine the above hypothesis.

\section{ACKNOWLEDGEMENTS}

We wish to thank Mr Ahmed Ellaboudy for his help with the flame emission experiments, and $\mathrm{Mr}$ James Topper for expert assistance in the gel electrophoresis experiments. This research was supported by USDA CRGO grant no.5901-0410-9. 0344 (G.T.B.) and NSF grant no. PCM 8214240 (C.F.Y.).

\section{REFERENCES}

[1] Ghanotakis, D.F., Babcock, G.T. and Yocum, C.F. (1983) submitted.

[2] Kuwabara, T. and Murata, N. (1983) Plant Cell Physiol. 24, 741-747.

[3] Åkerlund, H.E., Jansson, C. and Andersson, B. (1982) Biochim. Biophys. Acta 681, 1-10.

[4] Murata, N., Miyao, M. and Kuwabara, T. (1983) in: The Oxygen Evolving System of Photosynthesis (Inoue, Y. et al. eds) pp.213-222, Academic Press, Tokyo.

[5] Ghanotakis, D.F. and Babcock, G.T. (1983) FEBS Lett. 153, 231-234.

[6] Chua, N.H. (1980) in: Methods in Enzymology (San Pietro, A. ed) vol.69, pp.434-446, Academic Press, New York.

[7] Ghanotakis, D.F., Yerkes, C.T. and Babcock, G.T. (1982) Biochim. Biophys. Acta 682, 21-31.

[8] Piccioni, R.G. and Mauzerall, D.C. (1978) Biochim. Biophys. Acta 504, 384-397.

[9] Brand, J.J., Mohanty, P. and Fork, D.C. (1983) FEBS Lett. 155, 120-124.

[10] Barr, R., Troxel, K.S. and Crane, F.L. (1983) Plant Physiol. 72, 309-315.

[11] Yamashita, T. and Tomita, G. (1974) Plant Cell Physiol. 15, 69-82. 